\title{
Reproductive Impact of Cervical Conization
}

\author{
Annick Pina • Stéphanie Lavallée • Cathy Ndiaye • \\ Marie-Hélène Mayrand
}

Published online: 20 March 2013

(C) Springer Science+Business Media New York 2013

\begin{abstract}
Excisional procedures, such as loop electrosurgery (LEEP) and cold knife conization, are recommended treatments for cervical intraepithelial dysplasia (CIN). CIN and excisional treatments are associated with an increased risk of preterm delivery and premature rupture of membranes. This association is fairly consistent across studies focusing on cold knife conization, procedures removing deeper tissue specimens, and repeat procedures. Because the association is not as strong or consistent for single, shallow LEEPs, it is possible that the increased risk may be related, at least partly, to other factors (confounding). To prevent complications, treatment guidelines should be strictly followed to minimize overtreatment. General measures to prevent preterm birth, such as screening and treating infections and smoking cessation should be considered. Given the lack of evidence on the impact of progesterone to prevent preterm delivery in this population, further studies will be needed to determine if transvaginal sonographic cervical
\end{abstract}

\footnotetext{
A. Pina $\cdot$ S. Lavallée

Obstetrics \& Gynecology Department, Université de Montréal, CHUM, Hôpital St-Luc, 1058 Saint-Denis, Porte 5213, Montreal, Quebec H2X 3J4, Canada

A. Pina

e-mail: annick.orvoine.serra.pina@umontreal.ca

S. Lavallée

e-mail: stephanie.lavallee.2@umontreal.ca

C. Ndiaye

Research Center, Centre Hospitalier de l'Université de Montréal (CRCHUM), 3875, Saint-Urbain, porte 305,

Montreal, Quebec H2W 1V1, Canada

e-mail: cathy.ndiaye@crchum.qc.ca

M.-H. Mayrand $(\square)$

Obstetrics \& Gynecology and Social \& Preventive Medicine

Departments, Université de Montréal et CRCHUM,

3875, Saint-Urbain, porte 323,

Montreal, Québec H2W 1V1, Canada

e-mail: marie-helene.mayrand@umontreal.ca
}

length measurement should be offered routinely during pregnancy.

Keywords Cervical cancer prevention · Cervical intraepithelial dysplasia $\cdot$ Loop electrosurgery $\cdot$ Cold knife conization $\cdot$ Laser conization $\cdot$ Preterm labor $\cdot$ Preterm delivery $\cdot$ Premature rupture of membranes $\cdot$ Cerclage . Progesterone · Cervical length · Neonatal morbidity · Management of human papillomavirus and associated cervical lesions

\section{Introduction}

Cervical cancer is the third most frequent cancer in women worldwide [1]. It is caused by the infection of the cervical epithelium by oncogenic human papillomavirus (HPV) [2] When such an infection is not cleared by the immune system but persists, gradual disruption of the epithelium of the transformation zone can occur [3]. Such precancerous changes were traditionally designated as cervical intraepithelial neoplasia (CIN) and graded according to the depth of disruption. CIN1 lesions (or low-grade squamous intraepithelial lesions (LSIL)) involve less than one third of the epithelium, CIN2 up to two thirds, and CIN3 (or high-grade squamous intraepithelial lesions (HSIL)) between two thirds and the full-thickness of the epithelium, the latter also referred to as carcinoma in situ (CIS). New terminology guidelines suggest that further molecular diagnostic studies should be conducted on biopsy specimens of CIN2 to better characterize the potential for progression to cancer, and either upgrade the diagnosis to HSIL or downgrade it to LSIL according to these results $[4 \cdot \bullet]$.

Follow-up studies have confirmed that LSIL (CIN1) most often regresses spontaneously, and for this reason treatment of LSIL (CIN1) is no longer recommended [5]. On the other hand, CIS will progress to cancer in approximately $30 \%$ of 
cases [6], warranting treatment for such lesions [5]. Fortunately, progression from HPV infection, to precancerous lesion, to cancer is usually slow, in order of decades $[6,7]$. This probably explains why cervical cancer screening has been so successful in decreasing both incidence and mortality from cervical cancer in settings with integrated screening/diagnosis/treatment programs. Indeed, repeated screening with the Pap test (with or without HPV testing) can select women most at risk for $\mathrm{CIN} /$ cancer in order to refer them for a diagnostic workup, consisting of colposcopy and biopsy. If HSIL is identified on biopsy, treatment will prevent its progression to cancer. Traditionally ablative and excisional treatments have been used to destroy/resect the transformation zone. The fact that ablative treatments may be associated with more frequent failures [8, 9], and the development of simple, lowcomplication excisional procedures suited for outpatient settings, have caused ablative procedures to be gradually abandoned for HSIL treatment in developed countries.

The discovery in the 1940s of the possibility to identify early cancers by cytological testing [10], and thus improve outcome by early treatment, led to enthusiastic incorporation of these procedures in clinical practice in resource-rich settings, even before solid evidence of efficacy and risk of harm was available. However, a better understanding of the natural history of HPV infections and CIN, coupled with the reports of deleterious obstetrical impacts of excisional treatments, demand that we carefully consider whom we treat, and the potential implications of such treatments. In the following chapter, we will review the evidence of the impact of CIN excisional treatments on different reproductive outcomes, with the goal to provide an up-to-date summary on the topic.

\section{Excisional Treatments}

Excisional treatments (also referred to as conization) involve removing the HSIL lesion(s) with the entire transformation zone. This can be accomplished by a variety of tools; the most common are loop electrosurgery (LEEP or LLETZ) and cold knife conization [5]. Cold knife conization was the first fertility-sparing treatment used for HSIL. LEEP was later described in 1989 by Prendiville et al. [11] and has since become the most frequently used conization technique.

\section{Fertility}

Infertility

Several mechanistic causeways have been proposed as to how excisional treatments could negatively impact fertility [12]. The first is mechanical and consists of distortion of the endocervical canal and/or cervical stenosis that can, in theory, limit the entry of sperm in the uterine cavity [12-14]. The second is insufficient cervical mucus that could result from removal of cervical glands during conization [15]. Cervical mucus has many roles in fertility, including asepsis of the uterine cavity secondary to the presence of leucocytes, maintenance of an alkaline $\mathrm{pH}$ that enhances sperm viability, and facilitator for sperm transport $[14,16]$. The third cause is post procedure infection, which could damage the fallopian tubes [12].

Unfortunately, the exact impact of conization on fertility is not well known, because there are very few methodologically sound studies that address this particular problem. Reassuringly, available data suggest that conization does not increase the risk of infertility [14, 17-20]. Ideally, future studies on the topic should focus specifically on infertility (i.e., inability to conceive after trying for more than 12 months), use appropriate control group(s), and include large groups of treated women to conduct subgroup analysis investigating the role of the different conization techniques, as well as other factors, such as cone height and volume, time between conization, and trying to conceive, and should control for risk factors of infertility (maternal age, tubal factors, male factor, etc.).

\section{Spontaneous Abortions}

There is no evidence that conization increases the risk of first trimester abortions [17, 21]. This is not surprising because chromosomal abnormalities are thought to be involved in most early spontaneous pregnancy losses [22]. However, because conization involves removing part of the cervix, second trimester pregnancy losses due to cervical incompetence from lack of mechanical support are more worrisome [14]. This outcome has not been the focus of a meta-analysis. A population-based Norwegian study compared birth after conization (all techniques, mostly cold knife conization) with (a) births before conization, and (b) births in women who had never had conization. They controlled for maternal age and found an adjusted relative risk (RR) of late abortion (birth before 24 weeks and/or below $500 \mathrm{~g}$ ) to be tripled (RR $3.2 ; 1.5 \%$ vs. $0.4 \%$ crude risks) [23]. Older reports also have underlined the association between cold knife conization and second trimester pregnancy losses [24, 25], specifically with cone heights $>2 \mathrm{~cm}$ ) [26]. We could not find reports on the risk of late abortions specifically following LEEP.

\section{Assisted Reproductive Technologies}

We identified one study looking specifically at the need for IVF after conization [18]. The authors found no increased use of IVF in women who had conization compared with the 
general population, but the nature of the study (registerbased) made it impossible to control for confounding. Some have indicated that intrauterine insemination and embryo transfer can be more difficult in women with cervical stenosis [13]. Cervical stenosis has been reported to complicate up to $17 \%$ of conizations [16]. The risk of stenosis is increased when the height of the cone is over $2 \mathrm{~cm}$, the lesion is completely endocervical and in women older than age 50 years $[16,27]$.

Impact of Conization on Fertility: Summary of Main Findings

Available data do not suggest that excisional treatments are associated with an increased risk of infertility, first trimester pregnancy losses, or need for IVF. Cold knife conization appears to triple the risk of second trimester pregnancy losses. We did not find data looking specifically at the association between LEEP and second trimester pregnancy losses.

\section{Obstetrical Outcomes}

Although there are a number of studies on the risk of poor obstetrical outcomes following cervical conization, it remains a challenge to firmly establish causality. Observational studies most often cannot clearly differentiate between the role of (a) the disease (CIN), (b) patient characteristics/behaviors that led to the disease (and may also increase the risk of poor obstetrical outcome), and (c) the treatment (conization). Only a very large randomized trial, recruiting women with histological HSIL and comparing watchful waiting to LEEP to cold knife cone would provide a clear answer. Such a study obviously will never be done for ethical reasons. We must then examine available observational studies and reach the soundest conclusions, even if observational studies focusing on the association between conization and preterm delivery have inherent limitations. They cannot always distinguish between spontaneous and iatrogenic preterm delivery, especially when a register-based design is used. They may not be able to control for important confounders (age, smoking, previous preterm delivery, STIs, etc.) or to differentiate the effect size of different conization techniques (cold knife conization vs. LEEP).

\section{Preterm Delivery}

Preterm birth is defined as birth before completion of 37 weeks of pregnancy. It complicates $5-13 \%$ of pregnancies in developed countries and is responsible for more than $50 \%$ of neonatal morbidity and $75 \%$ of mortality [28]. We have summarized in Table 1 the main results of four metaanalyses on this specific topic $[19,29,30 \bullet, 31 \bullet \cdot$. The studies included in the meta-analysis mainly used "external" comparison groups, i.e., women without CIN and as such without a history of conization. The four reports found a significant increased risk for preterm delivery following cold knife conization, with relative risks (RRs) in the order of 2.59-3.41. The RR estimates for preterm

Table 1 Selected summary measure of risk from meta-analyses, specific for excisional treatment modality

\begin{tabular}{|c|c|c|c|c|c|c|c|}
\hline & Modality & pPROM & $\begin{array}{l}\text { Preterm birth } \\
<37 \text { weeks }\end{array}$ & $\begin{array}{l}\text { Preterm birth } \\
<28 / 30 \text { weeks }\end{array}$ & $\begin{array}{l}\text { Perinatal } \\
\text { mortality }\end{array}$ & $\begin{array}{l}\text { Birth weight } \\
<2500 \text { g }\end{array}$ & $\begin{array}{l}\text { Birth weight } \\
<1000 \mathrm{~g}\end{array}$ \\
\hline Kyrgiou et al. 2006 [19] & $\mathrm{CKC}$ & & $\begin{array}{l}\mathbf{2 . 5 9} \\
1.8-3.72\end{array}$ & & $\begin{array}{l}1.89 \\
0.77-4.65\end{array}$ & $\begin{array}{l}\mathbf{2 . 5 3} \\
1.19-5.36\end{array}$ & \\
\hline Arbyn et al. 2008 [30•] & $\mathrm{CKC}$ & & $\begin{array}{l}\mathbf{2 . 7 8} * \\
1.72-4.51\end{array}$ & $\begin{array}{l}\mathbf{5 . 3 3} \\
1.63-17.4\end{array}$ & $\begin{array}{l}2.87 \\
1.42-5.81\end{array}$ & $\begin{array}{l}\mathbf{2 . 8 6} * \\
1.37-5.97\end{array}$ & $\begin{array}{l}2.3 \\
0.73-7.25\end{array}$ \\
\hline $\begin{array}{l}\text { Bruinsma and Quinn } \\
2011[31 \bullet \bullet]\end{array}$ & $\mathrm{CKC}$ & & $\begin{array}{l}3.41 \\
2.38-488\end{array}$ & & & & \\
\hline Crane 2003 [29] & LEEP & & $\begin{array}{l}\mathbf{1 . 8 1} \\
1.81-2.76\end{array}$ & & & $\begin{array}{l}\mathbf{1 . 6} \\
1.01-2.52\end{array}$ & \\
\hline Kyrgiou et al. 2006 [19] & LEEP & $\begin{array}{l}\mathbf{2 . 6 9} \\
1.62-4.46\end{array}$ & $\begin{array}{l}\mathbf{1 . 7} \\
1.24-2.35\end{array}$ & & $\begin{array}{l}3.4 \\
0.62-18.63\end{array}$ & $\begin{array}{l}1.82 \\
1.09-3.06\end{array}$ & \\
\hline Arbyn et al. $2008\left[30^{\bullet}\right]$ & LEEP & & $\begin{array}{l}1.2^{*} \\
0.5-2.89\end{array}$ & $\begin{array}{l}\text { No pooled estimate } \\
\text { RR: } 0.44-2.67\end{array}$ & $\begin{array}{l}1.17 \\
0.74-1.87\end{array}$ & $\begin{array}{l}1.29^{* *} \\
0.42-4\end{array}$ & $\begin{array}{l}0.81 \\
0.11-5.81\end{array}$ \\
\hline $\begin{array}{l}\text { Bruinsma and Quinn } \\
2011[31 \bullet \bullet]\end{array}$ & LEEP & & $\begin{array}{l}\mathbf{1 . 8 5} \\
1.59-2.15\end{array}$ & & & & \\
\hline
\end{tabular}

Significant results are in bold

*Preterm defined as less than $32 / 24$ weeks

**Birth weight less than $2000 \mathrm{~g}$ 
delivery (less than 37 weeks) after LEEP also were very consistent, ranging from 1.70 to 1.85 . Arbyn et al. specifically focused on more severe outcomes and identified an increased risk of preterm delivery before $28 / 30$ weeks (RR 5.33; $95 \%$ confidence interval (CI) 1.63-17.4) after cold knife conization, as well as an increase in risk of perinatal mortality (RR 2.87; $95 \%$ CI 1.42-5.81) [30•]. There was no significant association between "severe pregnancy outcomes" and LEEP [30•].

Others have tried to identify characteristics of treatments, apart from the specific modality that could influence risk of preterm delivery. In his meta-analysis, Kyrgiou et al. reported an increased risk (RR 2.6; $95 \%$ CI 1.3-5.3) of preterm delivery when LEEPs deeper than $10 \mathrm{~mm}$ were compared with those less than $10 \mathrm{~mm}$ [19]. Other studies have since then confirmed the importance of the depth of excised tissue (over 1.7-2.5 mm) in relation to preterm delivery [32-35]. Repeat procedures have been shown to be especially detrimental $[33,36]$. Finally, there is some evidence that a shorter time interval between conization and pregnancy may increase the risk of preterm delivery [37-41].

To better ascertain the "amount of risk" pertaining to the procedure per se, as opposed to CIN or risk factors for CIN, Bruinsma et al. investigated through a meta-analysis how comparison groups influenced study estimates for risk of preterm delivery $[31 \bullet \bullet]$. When all excisional treatments were examined as a group, the RRs were highest when an external comparator (women without CIN) was used (RR 2.19; $95 \%$ CI 1.93-2.49) and lowest (and not statistically significant) when the comparison group included women with CIN who were not treated (RR 1.25; $95 \%$ CI 0.98-1.18]. These findings underline the fact that preterm delivery and HSIL share risk factors, and women with CIN are probably at increased risk for preterm delivery even if not treated.

Recently, a large study focused on women evaluated and/or treated in large colposcopy units in England. The study used different comparison groups. Most of the women treated had LEEP [42••]. The authors showed that as a group, women evaluated (and not necessarily treated) in a colposcopy clinic had an increased risk of preterm delivery compared with the general population (RR 1.31; $95 \% \mathrm{CI}$ $1.25-1.37)$. The RR increased to $1.41(1.29-1.54)$ in women who received treatment compared with the general population). However, when women who underwent treatment were compared to women who had a biopsy but no treatment, the RR decreased to 1.19 (95\% CI 1.01-1.41). Finally, an analysis restricted to 372 women who gave birth both before and after treatment did not find an increased risk for preterm delivery after treatment (RR 0.94; $95 \%$ CI $0.62-1.43$ ). These results highlight that most of the increased risk of preterm birth in women who have LEEP may be in fact due to risk factors for the disease and/or the disease itself, rather than related to LEEP.
Premature Rupture of Membranes

Membrane rupture is considered premature (PROM) when it occurs at least 1 hour before the onset of labor [28]. It also can be described as preterm (pPROM) when it takes place before 37 weeks of gestation. Studies that measure the association between conization and pPROM are as fraught with difficulties as those that focus on preterm delivery, and similar confounding factors are at play. The meta-analysis by Kyrgiou et al. included three studies for the association between LEEP and pPROM [19]. They reported a RR of 2.69 (1.62-4.46]. Arbyn and Bruinsma did not report specifically on pPROM or PROM in their meta-analysis [30•, $31 \bullet \bullet$. Studies published more recently also have found a threefold increase of pPROM in women with a history of LEEP compared with women with no conization and up to fourfold after cold knife conization [36]. Shanbhag et al. found an increased risk of PROM in women with CIN3 compared with women with no CIN (RR 1.27; $95 \%$ CI 1.09-1.48), but no significant difference when comparing women with CIN3 who underwent conization (almost exclusively LEEP) and those who did not receive treatment (RR 1.52; $95 \%$ CI 0.52-4.4) [43]. As is the case for preterm delivery, repeated procedures further increase the risk [36].

\section{Labor and Delivery}

In our experience, patients with a history of conization can present in labor with a palpable fibrous ring on their cervix. We have wondered if this could lead to a longer latency period until the ring "tears." Some have reported that prior conization reduces the length of active labor [44], whereas others have found no association [21]. Cervical conization is not associated with an increased risk of labor induction or operative deliveries (vacuum, forceps, cesarean) [21, 35, 44-48]. One report found an increased risk of spontaneous cervical tear during delivery in women who had a cold knife conization (OR 7.53; $95 \%$ CI 2.63-17.57; $p<0.001$ ) [48]. One study suggests an increase use of epidural during labor [49]. This may be linked to our perceived sometimesprolonged latency phase.

Impact of Conization on Obstetrical Outcomes: Summary of Main Findings

Women who have CIN are at increased risk of preterm delivery and premature rupture of membranes. Recent evidence suggests that LEEP may not increase the risk of preterm delivery further. Deep excisions, cold knife conization (compared to LEEP), repeat procedures, and short conization-pregnancy intervals further increase the risk of 
preterm birth. Excisional treatments do not appear to have a significant impact on the labor and delivery process.

\section{Neonatal Outcomes}

We will briefly review the impact of excisional treatments on neonatal outcomes. It is important to understand that the link between conization and neonatal outcomes is preterm birth. Prematurity, if associated with conization, will inevitably lead to lower birth weights, increased intensive care unit admissions, increased morbidity, and if extreme prematurity is sufficiently frequent to higher neonatal mortally. In their 2006 meta-analysis, Kyrgiou et al. showed that LEEP and cold knife conization both significantly increased low birth weight (RR 1.82; $95 \%$ CI 1.09-3.06; RR 2.53; $95 \%$ CI 1.19-5.36, respectively) [19]. In the updated metaanalysis in 2008, Arbyn et al. found that cold knife conization significantly increased the risk of very low (below 2000 g) birth weight (RR 2.86; $95 \%$ CI 1.375.97), perinatal mortality (RR 2.87; $95 \%$ CI 1.42-5.81), severe (RR 2.78; $95 \%$ CI 1.72-4.51), and extreme (RR 5.33; $95 \%$ CI 1.63-17.4) prematurity. The study did not find a significant association between those severe adverse outcome and LEEP [30•].

Since 2008, many more studies have looked at the link between cervical conization and neonatal outcomes [36, 43, 45, 47, 49-53]. Most have used comparison groups from the general population [45, 47, 49-51]. They did not report the type of conization and mostly provided estimates of risk for the different procedures combined [36, 45, 47, 49-51]. Compared to the general population, women with CIN who underwent treatment, on average, delivered babies with a lower mean birth weight, an increased risk of low birth weight, an increased risk of intensive care unit admission, and mortality, even after controlling for confounding. Three reports, all focusing exclusively on LEEP, included two types of control groups: one from the general population and another comprised of women with CIN who either were not treated [43], or had CIN and treatment after the pregnancy $[52,53]$. All three failed to identify a significantly increased risk of adverse neonatal outcome secondary to LEEP $[43,52,53]$, as they did not find an increase in preterm delivery.

Impact of Conization on Neonatal Outcomes: Summary of Main Findings

Newborns of women who have had CIN are at increased risk of poor neonatal outcome, as a result of an increased risk of prematurity. LEEP does not seem to further increase the risk of poor neonatal outcomes, above the risk of CIN.

\section{Management to Minimize Reproductive Complications Following Conization}

\section{Before Pregnancy}

At a population level, the best prevention consists of reducing the frequency of cervical conization. Hopefully, widespread HPV vaccination before onset of sexual activity will translate in a significant decrease in HSIL and need for conization. New cervical cancer screening guidelines suggesting delaying initiation of screening and longer intervals should help to limit overtreatment [54・•]. Quality assurance measures should monitor adherence to guidelines, ensuring that treatment of LSIL in women of childbearing age remains rare. Colposcopy units and pathology laboratories should ensure that CIN2 (by the old nomenclature) is "triaged" with appropriate molecular biomarkers. Studies have shown that a large proportion of such lesions will be downgraded to LSIL if stained for p16 [4••]. Because CIN and preterm delivery share risk factors, colposcopy visits may be a chance to educate women on risk factors for prematurity, provide smoking cessation counselling and pharmacological aids, and screen and treat for STIs.

For women who do need to be treated, LEEP should be favored over cold knife conization. The depth of tissue excision should be as small as possible, while aiming for complete lesion removal on first treatment. Women should be advised to defer pregnancy for several months.

\section{During Pregnancy}

Ever since studies have shown a possible increased risk of preterm delivery in women after conization, options were sought to prevent preterm delivery in this population. Routine placement of cervical cerclage was tried but did not prevent preterm delivery [55-57]. In the general obstetrical population, the American College of Obstetricians and Gynecologists has recognized that cervical length measurement by transvaginal ultrasound can be used as a screening tool for preterm delivery [58]. The recommendations address separately women who have had a prior preterm delivery and those who have not. Women who are found to have a cervix of $25 \mathrm{~mm}$ or less at or before 24 weeks are to be offered vaginal progesterone supplementation [58]. Cerclage is not recommended for women without a history of preterm delivery with a short cervix on screening ultrasound [58].

The value of cervical length screening to predict/prevent preterm birth has been evaluated in women with a history of conization. A few studies used transvaginal ultrasound to evaluate the impact of conization on cervical 
length, outside of pregnancy. No difference in cervical length before and after conization was found when the second ultrasound was performed several months after treatment [40]. Others identified a shorter cervix in the immediate postoperative period $[38,39,41]$ but concluded that the defect had essentially disappeared by 6 months [41].

When transvaginal ultrasound cervical length screening is performed during the second trimester of pregnancy, women with prior conization have, on average, a shorter cervix than women without a conization history by only by $0.56-0.67 \mathrm{~cm}[59,60]$. The clinical significance of such a small difference is unknown. Some reports indicate that transvaginal cervical length measurement cannot reliably predict preterm birth in pregnant women who previously had a conization at the usual cutoff of $25 \mathrm{~mm}$ of cervical length $[60,61]$. Others found a limited sensitivity in the $50-67 \%$ range $[59,62]$ and a positive predictive value of $22 \%$ [62].

We could not identify any reports focusing on the role of progesterone to prevent preterm delivery in otherwise lowrisk women with a prior conization and a short cervix on transvaginal ultrasound cervical length screening. It would be important that future intervention studies focus specifically on this population, because it is not certain that the benefits of ultrasound screening/progesterone would necessarily apply to women who have undergone excisional treatment for CIN. If we hypothesize that a short cervix is usually the result of a physiological process ("preclinical" labor [63] or "relative" cervical incompetency [64]), then, in the general population, a short cervix on screening ultrasound would be a marker for this physiological process. Progesterone would prevent preterm birth by halting the process. However, the finding of a short cervix after excisional treatment may only indicate that some cervical tissue was removed. Progesterone is not expected to influence this in any way. On the other hand, if a "structurally" short cervix predates the initiation of labor and increases the risk of preterm birth, for example, by increasing the risk of microbial contamination/inflammation of the uterine cavity [65], and progesterone reduces the uterine response to inflammation, then women with a short cervix caused by excisional treatment also could benefit from screening/treatment with progesterone.

Given the lack of evidence to support efficacious interventions to prevent preterm delivery in women with a short cervix and prior conization, it is difficult to recommend strongly routine screening by transvaginal ultrasound in this population.

As routine "cervical length screening followed by progesterone supplementation for women with a short cervix" is incorporated in some practices, some women with prior conization will be screened and treated. It is likely that a more comprehensive understanding of the benefits of this management strategy for women with an antecedent of conization will then emerge.

Preventive measures: Summary of Main Findings

Indications for conization should follow most recent guidelines to limit overtreatment. LEEP should be preferred to cold knife conization. Patients seen in the colposcopy clinic could benefit from general preventive counselling in relation to preterm delivery. It is unclear whether transvaginal ultrasound cervical length screening is a useful predictor of preterm birth in women with prior conization. No studies have evaluated the role of progesterone in this population. Routine cerclage is not indicated.

\section{Conclusions}

Women undergoing conization for HSIL are at higher risk for preterm delivery compared with the general population. Conization techniques that remove larger tissue specimens, such as cold knife conization or repeat procedures, seem to increase the risk even further. Cold knife conization also increases the risk of second-trimester pregnancy loss, premature rupture of membranes, and the complications of prematurity.

There is some recent reassuring evidence that when LEEPs are performed in large, quality-assured colposcopy units, preterm delivery risk may not be further increased above the risk associated with CIN (or its risk factors). The shallowest LEEP that will enable complete removal of the lesion should be performed. It may be safer for women to defer pregnancy for several months after conization.

The role of transvaginal ultrasound cervical length measurement to identify women at higher risk of preterm delivery in women with prior conization is controversial. It is difficult to recommend this procedure specifically for women who have undergone excisional treatment, because no study has evaluated the role of progesterone (or other treatments) in preventing adverse perinatal outcomes if a short cervix is found. The best way that we can limit the obstetrical complications of excisional treatments remains a judicious use of conization.

Conflict of Interest Annick Pina declares that she has no conflict of interest.

Stéphanie Lavallée declares that she has no conflict of interest. Cathy Ndiaye declares that she has no conflict of interest.

Marie-Hélène Mayrand received honoraria from Merck and GlaxoSmithKline. 


\section{References}

Papers of particular interest, published recently, have been highlighted as:

- Of importance

•- Of major importance

1. Jemal A, Bray F, Center MM, et al. Global cancer statistics. CA Cancer J Clin. 2011;61:69-90.

2. Walboomers JMM, Jacobs MV, Manos MM, et al. Human papillomavirus is a necessary cause of invasive cervical cancer worldwide. J Pathol. 1999;189:12-9.

3. Moscicki AB, Schiffman M, Kjaer S, Villa LL. Chapter 5: updating the natural history of HPV and anogenital cancer. Vaccine. 2006; 24 Suppl 3:S42-51.

4. •- Darragh TM, Colgan TJ, Cox JT, et al. The lower anogenital squamous terminology standardization project for HPV-associated lesions: background and consensus recommendations from the College of American Pathologists and the American Society for Colposcopy and Cervical Pathology. J Low Genit Tract Dis. 2012;16:205-42. Indirectly, by providing guidelines to reduce over diagnosis of HSIL, should have a significant impact to reduce obstetrical impact of conization at a population level.

5. Wright Jr TC, Massad LS, Dunton CJ, et al. 2006 consensus guidelines for the management of women with cervical intraepithelial neoplasia or adenocarcinoma in situ. J Low Genit Tract Dis. 2007;11:223-39.

6. McCredie MR, Sharples KJ, Paul C, et al. Natural history of cervical neoplasia and risk of invasive cancer in women with cervical intraepithelial neoplasia 3: a retrospective cohort study. Lancet Oncol. 2008;9:425-34.

7. Ostor AG. Natural history of cervical intraepithelial neoplasia: a critical review. Int J Gynecol Pathol. 1993;12:186-92.

8. Melnikow J, McGahan C, Sawaya GF, et al. Cervical intraepithelial neoplasia outcomes after treatment: long-term follow-up from the British Columbia Cohort Study. J Natl Cancer Inst. 2009;101:721-8.

9. Cecchini S, Ciatto S, Iossa A, et al. Re: cervical intraepithelial neoplasia outcomes after treatment: long-term follow-up from the British Columbia Cohort Study. J Natl Cancer Inst. 2009;101:1429-30.

10. Papanicolaou GN, Traut HF. The diagnostic value of vaginal smears in carcinoma of the uterus. 1941. Arch Pathol Lab Med. 1997;121:211-24.

11. Prendiville W, Cullimore J, Norman S. Large loop excision of the transformation zone (LLETZ). A new method of management for women with cervical intraepithelial neoplasia. Br J Obstet Gynaecol. 1989;96:1054-60.

12. Hammond RH, Edmonds DK. Does treatment for cervical intraepithelial neoplasia affect fertility and pregnancy? BMJ. 1990;301:1344-5.

13. Fox R, Cahill DJ. Fertility after treatment for cervical intraepithelial neoplasia. BMJ. 1991;302:179.

14. Montz FJ. Impact of therapy for cervical intraepithelial neoplasia on fertility. Am J Obstet Gynecol. 1996;175:1129-36.

15. Kennedy S, Robinson J, Hallam N. LLETZ and infertility. Br J Obstet Gynaecol. 1993;100:965.

16. Porcu G. Conséquences iatrogènes des techniques de traitement cervical. EMC - Gynécologie Obstétrique. 2005;2:181-4.

17. Ferenczy A, Choukroun D, Falcone T, Franco E. The effect of cervical loop electrosurgical excision on subsequent pregnancy outcome: North American experience. Am J Obstet Gynecol. 1995; 172:1246-50

18. Jakobsson M, Gissler M, Tiitinen A, et al. Treatment for cervical intraepithelial neoplasia and subsequent IVF deliveries. Hum Reprod. 2008;23:2252-5.
19. Kyrgiou M, Koliopoulos G, Martin-Hirsch P, et al. Obstetric outcomes after conservative treatment for intraepithelial or early invasive cervical lesions: systematic review and meta-analysis. Lancet. 2006;367:489-98.

20. Bigrigg A, Haffenden DK, Sheehan AL, et al. Efficacy and safety of large-loop excision of the transformation zone. Lancet. 1994;343:32-4.

21. Cruickshank ME, Flannelly G, Campbell DM, Kitchener HC. Fertility and pregnancy outcome following large loop excision of the cervical transformation zone. Br J Obstet Gynaecol. 1995;102:467-70.

22. Boue J, Bou A, Lazar P. Retrospective and prospective epidemiological studies of 1500 karyotyped spontaneous human abortions. Teratology. 1975;12:11-26.

23. Albrechtsen S, Rasmussen S, Thoresen S, et al. Pregnancy outcome in women before and after cervical conisation: population based cohort study. BMJ. 2008;337:a1343.

24. El-Bastawissi AY, Becker TM, Daling JR. Effect of cervical carcinoma in situ and its management on pregnancy outcome. Obstet Gynecol. 1999;93:207-12.

25. Moinian M, Andersch B. Does cervix conization increase the risk of complications in subsequent pregnancies? Acta Obstet Gynecol Scand. 1982;61:101-3.

26. Leiman G, Harrison NA, Rubin A. Pregnancy following conization of the cervix: complications related to cone size. Am J Obstet Gynecol. 1980;136:14-8.

27. Baldauf JJ, Dreyfus M, Ritter J, et al. Risk of cervical stenosis after large loop excision or laser conization. Obstet Gynecol. 1996;88:933-8.

28. Goldenberg RL, Culhane JF, Iams JD, Romero R. Epidemiology and causes of preterm birth. Lancet. 2008;371:75-84.

29. Crane JM. Pregnancy outcome after loop electrosurgical excision procedure: a systematic review. Obstet Gynecol. 2003;102:1058-62.

30. - Arbyn M, Kyrgiou M, Simoens C, et al. Perinatal mortality and other severe adverse pregnancy outcomes associated with treatment of cervical intraepithelial neoplasia: meta-analysis. BMJ. 2008;337:a1284. Most recent meta-analysis with summary measures for both LEEP and cold knife conization and both obstetrical and perinatal outcomes.

31. • Bruinsma FJ, Quinn MA. The risk of preterm birth following treatment for precancerous changes in the cervix: a systematic review and meta-analysis. BJOG. 2011;118:1031-41. First meta-analysis to provide summary measures of risk by grouping studies according to the type of comparator group. This study confirmed that some of the risk of preterm delivery is associated with CIN and/or CIN risk factors, independent of treatment and that the use controls from the general population overestimates the risk of treatments.

32. Sadler L, Saftlas A, Wang W, et al. Treatment for cervical intraepithelial neoplasia and risk of preterm delivery. JAMA. 2004;291:2100-6.

33. Jakobsson M, Gissler M, Paavonen J, Tapper AM. Loop electrosurgical excision procedure and the risk for preterm birth. Obstet Gynecol. 2009; 114:504-10.

34. Noehr B, Jensen A, Frederiksen K, et al. Depth of cervical cone removed by loop electrosurgical excision procedure and subsequent risk of spontaneous preterm delivery. Obstet Gynecol. 2009;114:1232-8.

35. Acharya G, Kjeldberg I, Hansen SM, et al. Pregnancy outcome after loop electrosurgical excision procedure for the management of cervical intraepithelial neoplasia. Arch Gynecol Obstet. 2005;272:109-12.

36. Ortoft G, Henriksen T, Hansen E, Petersen L. After conisation of the cervix, the perinatal mortality as a result of preterm delivery increases in subsequent pregnancy. BJOG. 2010;117:258-67. 
37. Himes KP, Simhan HN. Time from cervical conization to pregnancy and preterm birth. Obstet Gynecol. 2007;109:314-9.

38. Ricciotti HA, Burke L, Kobelin M, et al. Ultrasound evaluation of cervical shortening after loop excision of the transformation zone (LETZ). Int J Gynaecol Obstet. 1995;50:175-8.

39. Mazouni C, Bretelle F, Blanc K, et al. Transvaginal sonographic evaluation of cervix length after cervical conization. J Ultrasound Med. 2005;24:1483-6.

40. Gentry DJ, Baggish MS, Brady K, et al. The effects of loop excision of the transformation zone on cervical length: implications for pregnancy. Am J Obstet Gynecol. 2000;182:516-20.

41. Paraskevaidis E, Bilirakis E, Koliopoulos G, et al. Cervical regeneration after diathermy excision of cervical intraepithelial neoplasia as assessed by transvaginal sonography. Eur J Obstet Gynecol Reprod Biol. 2002;102:88-91.

42. • Castanon A, Brocklehurst P, Evans H, et al. Risk of preterm birth after treatment for cervical intraepithelial neoplasia among women attending colposcopy in England: retrospective-prospective cohort study. BMJ. 2012;345:e5174. Epidemiologically superb, this large retrospective study used a variety of control groups. It confirmed that most of the risk of preterm delivery is associated with CIN/ CIN risk factors, and that in the context of large, quality-assured colposcopy clinic, LEEP could carry minimal (if none) excess risk.

43. Shanbhag S, Clark H, Timmaraju V, et al. Pregnancy outcome after treatment for cervical intraepithelial neoplasia. Obstet Gynecol. 2009;114:727-35.

44. Paraskevaidis E, Koliopoulos G, Lolis E, et al. Delivery outcomes following loop electrosurgical excision procedure for microinvasive (FIGO stage IA1) cervical cancer. Gynecol Oncol. 2002;86:10-3.

45. van de Vijver A, Poppe W, Verguts J, Arbyn M. Pregnancy outcome after cervical conisation: a retrospective cohort study in the Leuven University Hospital. BJOG. 2010;117:268-73.

46. Samson SL, Bentley JR, Fahey TJ, et al. The effect of loop electrosurgical excision procedure on future pregnancy outcome. Obstet Gynecol. 2005;105:325-32.

47. Van Hentenryck M, Noel JC, Simon P. Obstetric and neonatal outcome after surgical treatment of cervical dysplasia. Eur J Obstet Gynecol Reprod Biol. 2012;162:16-20.

48. Klaritsch P, Reich O, Giuliani A, et al. Delivery outcome after cold-knife conization of the uterine cervix. Gynecol Oncol. 2006;103:604-7.

49. Armarnik S, Sheiner E, Piura B, et al. Obstetric outcome following cervical conization. Arch Gynecol Obstet. 2011;283:765-9.

50. Noehr B, Jensen A, Frederiksen K, et al. Loop electrosurgical excision of the cervix and risk for spontaneous preterm delivery in twin pregnancies. Obstet Gynecol. 2009;114:511-5.
51. Lima AF, Francisco C, Julio C, et al. Obstetric outcomes after treatment for cervical intraepithelial neoplasia: six years of experience. J Low Genit Tract Dis. 2011;15:276-9.

52. Werner CL, Lo JY, Heffernan T, et al. Loop electrosurgical excision procedure and risk of preterm birth. Obstet Gynecol. 2010;115:605-8.

53. Andia D, Mozo de Rosales F, Villasante A, et al. Pregnancy outcome in patients treated with cervical conization for cervical intraepithelial neoplasia. Int J Gynaecol Obstet. 2011;112:225-8.

54. •- Saslow D, Solomon D, Lawson HW, et al. American Cancer Society, American Society for Colposcopy and Cervical Pathology, and American Society for Clinical Pathology Screening Guidelines for the Prevention and Early Detection of Cervical Cancer. Am J Clin Pathol. 2012;137:516-42. Adhering to these guidelines could contribute to limit the obstetrical impact of conization, by initiating screening later, and lengthening the screening interval.

55. Zeisler H, Joura EA, Bancher-Todesca D, et al. Prophylactic cerclage in pregnancy. Effect in women with a history of conization. J Reprod Med. 1997;42:390-2.

56. Nam KH, Kwon JY, Kim YH, Park YW. Pregnancy outcome after cervical conization: risk factors for preterm delivery and the efficacy of prophylactic cerclage. J Gynecol Oncol. 2010;21:225-9.

57. Shin MY, Seo ES, Choi SJ, et al. The role of prophylactic cerclage in preventing preterm delivery after electrosurgical conization. $\mathrm{J}$ Gynecol Oncol. 2010;21:230-6.

58. Practice bulletin no. 130: prediction and prevention of preterm birth. Obstet Gynecol 2012; 120:964-973.

59. Crane JM, Delaney T, Hutchens D. Transvaginal ultrasonography in the prediction of preterm birth after treatment for cervical intraepithelial neoplasia. Obstet Gynecol. 2006;107:37-44.

60. Fischer RL, Sveinbjornsson G, Hansen C. Cervical sonography in pregnant women with a prior cone biopsy or loop electrosurgical excision procedure. Ultrasound Obstet Gynecol. 2010;36:613-7.

61. Parikh R, Horne H, Feinstein SJ, Anasti JN. Cervical length screening in patients who have undergone loop electrosurgical excision procedure. J Reprod Med. 2008;53:909-13.

62. Berghella V, Pereira L, Gariepy A, Simonazzi G. Prior cone biopsy: prediction of preterm birth by cervical ultrasound. Am J Obstet Gynecol. 2004;191:1393-7.

63. Berghella V. Novel developments on cervical length screening and progesterone for preventing preterm birth. BJOG. 2009;116:182-7.

64. Iams JD, Goldenberg RL, Meis PJ, et al. The length of the cervix and the risk of spontaneous premature delivery. National Institute of Child Health and Human Development Maternal Fetal Medicine Unit Network. N Engl J Med. 1996;334:567-72.

65. Masamoto $\mathrm{H}$, Nagai $\mathrm{Y}$, Inamine $\mathrm{M}$, et al. Outcome of pregnancy after laser conization: implications for infection as a causal link with preterm birth. J Obstet Gynaecol Res. 2008;34:838-42. 